University of Nebraska - Lincoln

DigitalCommons@University of Nebraska - Lincoln

1989

\title{
THE KATZ CELL-SURVIVAL MODEL AND BEAMS OF HEAVY CHARGED PARTICLES
}

Stanley B. Curtis

University of California - Berkeley

Follow this and additional works at: https://digitalcommons.unl.edu/usdoepub

Part of the Bioresource and Agricultural Engineering Commons

Curtis, Stanley B., "THE KATZ CELL-SURVIVAL MODEL AND BEAMS OF HEAVY CHARGED PARTICLES" (1989). US Department of Energy Publications. 88.

https://digitalcommons.unl.edu/usdoepub/88

This Article is brought to you for free and open access by the U.S. Department of Energy at DigitalCommons@University of Nebraska - Lincoln. It has been accepted for inclusion in US Department of Energy Publications by an authorized administrator of DigitalCommons@University of Nebraska - Lincoln. 


\title{
THE KATZ CELL-SURVIVAL MODEL AND BEAMS OF HEAVY CHARGED PARTICLES
}

\author{
Stanley B. Curtis \\ Cell and Molecular Biology Division, Lawrence Berkeley Laboratory, University of California, Berkeley,
} California 94720, U.S.A.

(Received 9 January 1989)

\begin{abstract}
In this paper, we describe how the Katz cell-survival model has been used to predict survival along the central axis of the dose vs depth curve of beams of heavy charged particles. Unmodified beams with sharp Bragg peaks as well as ridge-filter-modulated beams with spread Bragg peaks have been studied. The analysis in terms of this model leads to the definition of two coefficients, "ion kill" and "gamma kill", which characterize the radiation quality of the beams. In this way, the relative importance of the primary and secondary (fragmentation) contributions can be assessed easily.

Setting the model parameter $m$ equal to 2 yields two interesting results: the survival expression becomes linear-quadratic at low doses and the inactivation cross-section at small values of $Z^{* 2} / \beta^{2}$ (low-LET) increases as $\left(Z^{* 2} / \kappa \beta^{2}\right)^{2}$ in accordance with the Lethal-Potentially Lethal (LPL) model. With this restriction on $m$ and these approximations (low-LET and low dose) and for delayed plating experiments of stationary phase cells (i.e. when repair is complete), the Katz model and the LPL model reduce to the same analytical form (linear-quadratic) with simple expressions linking the constants.
\end{abstract}

\section{INTRODUCTION}

THE KATZ cell-survival model (Katz et al., 1971) is a convenient model for calculating survival for beams of particles with broad LET spectra. The prescription for how to handle different LETs can be specified easily and the calculations are straightforward. Interesting results are obtained by keeping the various LET contributions separate so that the relative importance of the secondary fragments in the beam can be determined. In addition, if one of the model parameters is fixed $(m=2)$, the model can be compared to other models of cell killing and simple relationships between constants are found at low dose and low LET.

\section{ANALYTICAL FORM OF THE MODEL}

The model as formulated for cell killing can be written in the following form:

$$
S=\mathrm{e}^{-\sigma D / L}\left\{1-\left[1-\mathrm{e}^{-(1-P)\left(D / D_{0}\right)}\right]^{m}\right\}
$$

where

$$
\begin{aligned}
& \sigma=\sigma_{0}\left(1-\mathrm{e}^{-Z^{* 2} / \kappa \cdot \beta^{2}}\right)^{m} \\
& P=\sigma / \sigma_{0}
\end{aligned}
$$

$D=$ the absorbed dose

$$
L=\mathrm{LET}
$$

$Z^{*}=$ the effective charge on the charged particle

$\beta=$ the velocity of the particle relative to that of light.
The four parameters of the model are $\sigma_{0}, \kappa, m$ and $D_{0} . \sigma_{0}$ has the dimensions of an area and can be interpreted as the effective cross-sectional area of the radiation-sensitive material in a cell nucleus; $m$ can be interpreted as a target number, $D_{0}$ as the reciprocal final slope of a low-LET or gamma ray survival curve and $\kappa$ are relating to the characteristics of an individual target. If $L$ is given in $\mathrm{keV} / \mu \mathrm{m}, \sigma$ in $\mu \mathrm{m}^{2}$, then $D$ is to be expressed in $\mathrm{keV} / \mu \mathrm{m}^{3}$.

\section{THE SITUATION FOR MIXED LET BEAMS}

For a beam of particles with various $Z^{*} \mathrm{~s}$ and $\beta \mathrm{s}$, the $\sigma \mathrm{s}$ are going to vary in accordance with equation (2) and $L$, of course, will also vary. With the assumption that each dose element $\mathrm{d} D$ makes an independent contribution to the exponents in equation (1), we can address the case of a mixed radiation field with LET spectra given by $D_{i}\left(L_{i}\right)$ where $i$ denotes the ion type $($ total $=N)$ and

$$
\int D_{i}\left(L_{i}\right) \mathrm{d} L_{i}=D_{i}
$$

where $D_{i}$ is the dose contribution of the $i$ th particle type.

$$
\begin{aligned}
& \text { Equation (1) becomes } \\
& S=\exp \left[-\sum_{i}^{N} \int \frac{\sigma_{i}}{L_{i}} D_{i}\left(L_{i}\right) \mathrm{d} L_{i}\right] \\
& \times\left\{1-\left[1-\exp \left[-\frac{1}{D_{0}} \sum_{i}^{N} \int\left(1-P_{i}\right) D_{i}\left(L_{i}\right) \mathrm{d} L_{i}\right]\right]^{m}\right\}
\end{aligned}
$$


where the summation is over all the particles in the beam: the primaries and the secondary fragments.

It is convenient to now separate the primaries from the secondaries, obtaining

$$
\begin{aligned}
S= & \exp \left[-\left\langle\frac{\sigma_{\mathrm{p}}}{L_{\mathrm{P}}}\right\rangle_{\mathrm{D}} D_{\mathrm{P}}-\sum_{i}^{N-1} \int \frac{\sigma_{i}}{L_{i}} D_{i}\left(L_{i}\right) \mathrm{d} L_{i}\right] \\
& \times\left\{1-\left[1-\exp \left[-\left\langle 1-P_{\mathrm{P}}\right\rangle_{\mathrm{D}} D_{\mathrm{P}} / D_{0}\right.\right.\right. \\
& \left.\left.\left.-\sum_{i}^{N-1} \int \frac{\left(1-P_{i}\right)}{D_{0}} D_{i}\left(L_{i}\right) \mathrm{d} L_{i}\right]\right]^{m}\right\} .
\end{aligned}
$$

Here the integrals over the primary particle spectra have been replaced by the products of the appropriate dose-averaged quantities and the absorbed dose due to the primaries through the relationship defining the dose-averaged quantities:

$$
\begin{aligned}
\left\langle\frac{\sigma_{\mathrm{P}}}{L_{\mathrm{P}}}\right\rangle_{\mathrm{D}} & =\frac{\int \frac{\sigma_{\mathrm{P}}}{L_{\mathrm{P}}} D_{\mathrm{P}}\left(L_{\mathrm{P}}\right) \mathrm{d} L_{\mathrm{P}}}{\int D_{\mathrm{P}}\left(L_{\mathrm{P}}\right) \mathrm{d} L_{\mathrm{P}}} \\
\left\langle 1-P_{\mathrm{P}}\right\rangle_{\mathrm{D}} & =\frac{\int\left(1-P_{\mathrm{P}}\right) D_{\mathrm{P}}\left(L_{\mathrm{P}}\right) \mathrm{d} L_{\mathrm{P}}}{\int D_{\mathrm{P}}\left(L_{\mathrm{P}}\right) \mathrm{d} L_{\mathrm{P}}} .
\end{aligned}
$$
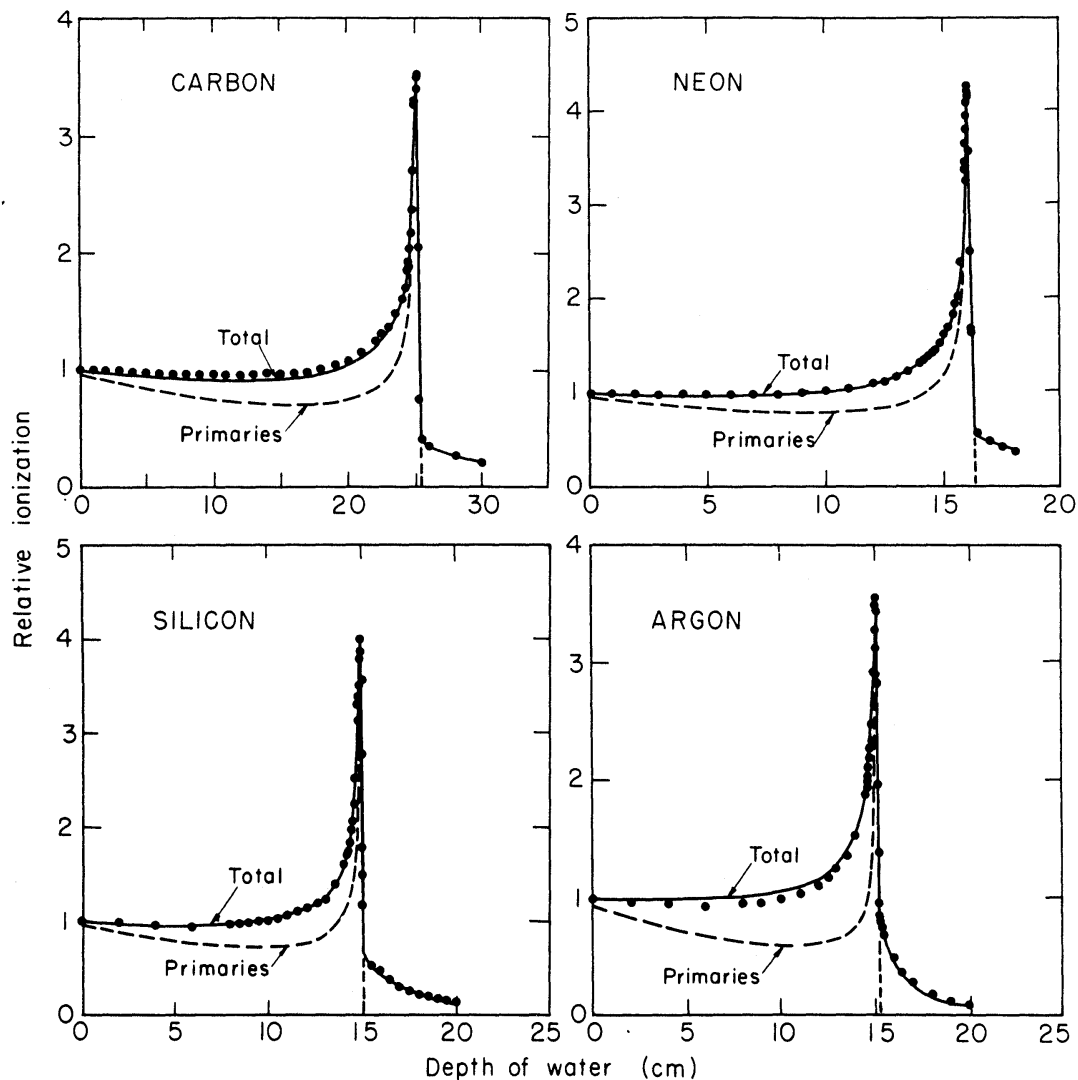

FIG. 1. Central axis dose vs depth curves (solid lines) calculated from the HZESEC computer code for four different unmodified heavy charged particle beams: a carbon beam with a range of $25 \mathrm{~cm}$ of water, and neon, silicon and argon beams with ranges of $15 \mathrm{~cm}$ of water. The solid circles are experimental data obtained from parallel plate ionization chambers placed on each side of a variable water column. The dashed curves are the calculated contributions from the primary particles only. 
CONTRIBUTION TO ION KILL FOR OXYGENATED CELLS
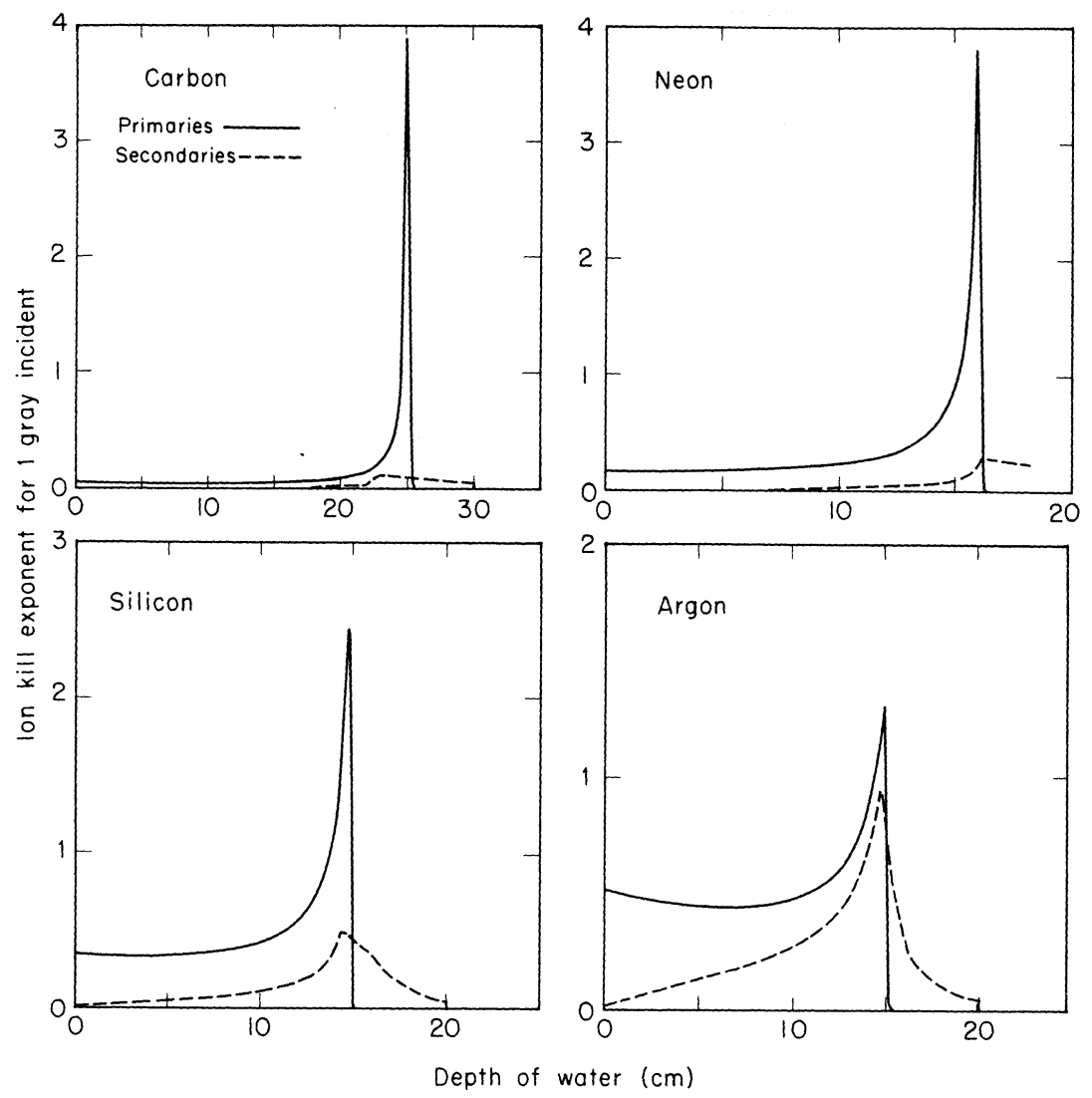

FIG. 2. Ion kill exponents (i.e. ion kill coefficients as defined in the text multiplied by the dose) for $1 \mathrm{~Gy}$ absorbed at the water surface plotted against water absorber as calculated for the four beams described in Fig. 1. The solid lines are the contributions from the primary particles and the dashed lines are the contributions from the secondary fragments. The differences occurring at the surface (zero depth) reflect the differences in biological response for the incident LETs for the different beams. The variation of values along the $X$-axis result from the variation of both the absorbed dose and the biological response per unit dose for the "ion kill" mode.

dose curves for the unmodified carbon, neon, silicon, and argon beams obtained at the Berkeley BEVALAC accelerator. The carbon beam had a range of about $25 \mathrm{~cm}$ of water while the others had ranges of about $15 \mathrm{~cm}$. The experimental data (solid circles) are shown in comparison to the calculated values for the total dose (solid line). The contributions from the primaries are shown in each case as dashed lines. This code calculates LET spectra for the secondaries and primaries before integrating to obtain the total dose. These spectra were used to calculate the ion and gamma kill coefficients* as a function of depth for these four beams. The results are shown in Fig. 2 for the ion kill coefficient, with the coefficient for the primaries as a solid line, and for the secondaries as a dashed line, calculated for $1 \mathrm{~Gy}$ incident (i.e. at zero water depth). The four examples are for the same four beams shown in Fig. 1. Results for the gamma kill coefficient are shown in Fig. 3. We note that the gamma coefficient dominates the ion kill coefficient at shallow depth for all the beams except argon, where the two are comparable. However, in the peak region, the ion kill coefficient dominates for all beams. The secondaries are not important for the carbon beam, but for the heavier beams the secondaries play an increasingly important role in both coefficients and become as important as the primaries for the argon ion beam.

\section{FRACTION OF CELL KILLING BY TWO LET COMPONENTS}

If we denote the ion and gamma kill coefficients as $I_{\mathrm{P}}$ and $G_{\mathrm{P}}$ respectively for the primaries and $I_{\mathrm{S}}$ and $G_{\mathrm{S}}$ for the secondaries, equation (9) becomes

$$
S=\mathrm{e}^{-I_{\mathrm{P}} D_{\mathrm{P}}-I_{\mathrm{S}} D_{\mathrm{S}}}\left\{1-\left[1-\mathrm{e}^{-G_{\mathrm{P}} D_{\mathrm{P}}-G_{\mathrm{S}} D_{\mathrm{S}}}\right]^{m}\right\} .
$$

\footnotetext{
*The values used for the parameters were: $\sigma_{0}=67 \mu \mathrm{m}^{2} ; \kappa=1000 ; D_{0}=1.7 \mathrm{~Gy}$; and $m=2.5$. [These as well as the hypoxic values given in the second footnote come from a best-fit procedure for families of experimental data on $T-1$ human cells from Todd (1967).]
} 
CONTRIBUTION TO GAMMA KILL FOR OXYGENATED CELLS
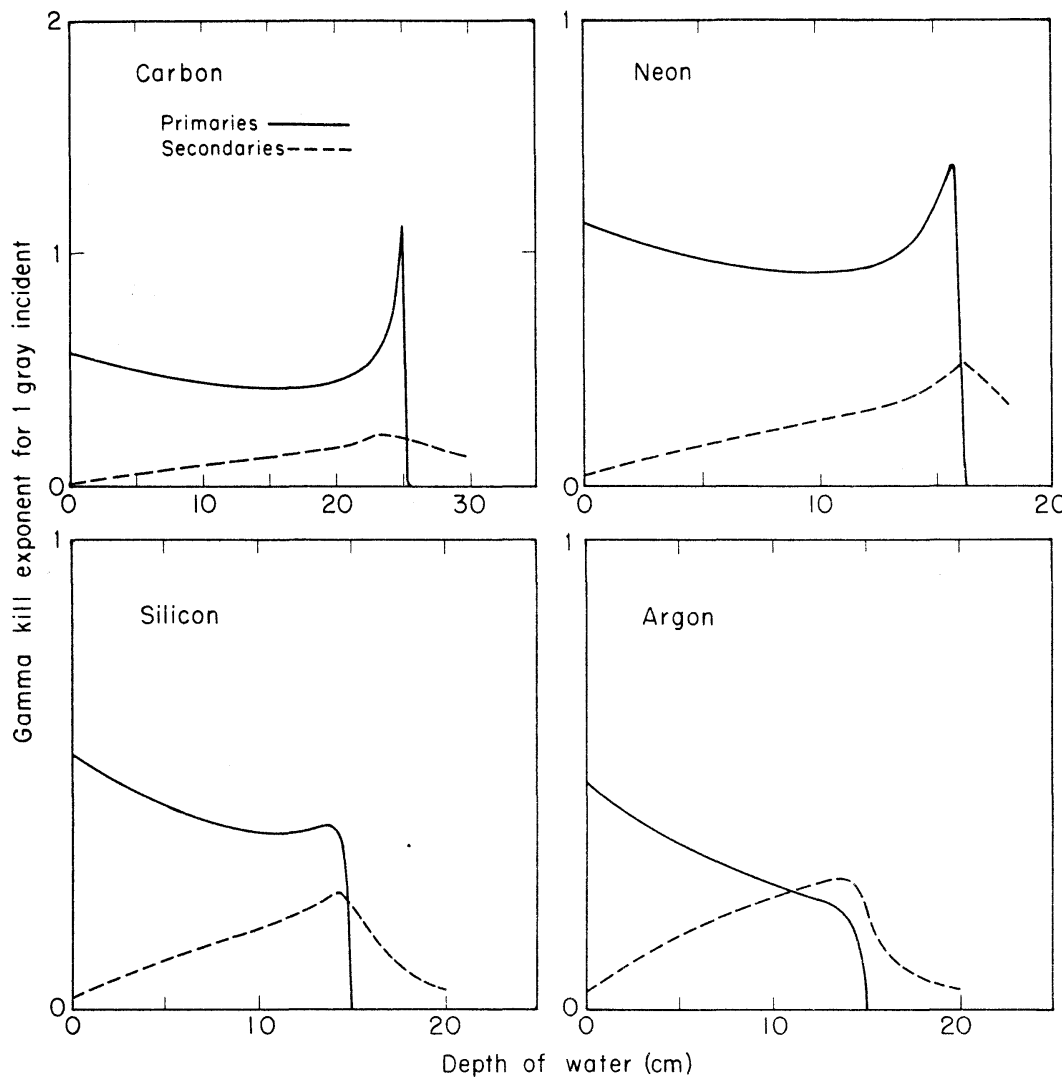

Fig. 3. Gamma kill exponents (i.e. gamma kill coefficients as defined in the text multiplied by the dose) for $1 \mathrm{~Gy}$ incident at the water surface plotted for the same conditions as in Fig. 2. Here all beams produce roughly the same gamma kill response at the surface (zero depth). The variation along the $X$-axis reflects both the variation of biological response and the variation of dose.

The fractional cell killing $K_{\mathrm{P}}$ due to primaries only is

$$
K_{\mathrm{P}}=1-S_{\mathrm{P}}=1-\mathrm{e}^{-I_{\mathrm{P}} D_{\mathrm{P}}}\left\{1-\left[1-\mathrm{e}^{-G_{\mathrm{P}} D_{\mathrm{P}}}\right]^{m}\right\}
$$

and $K_{\mathrm{S}}$ due to secondaries only is

$$
K_{\mathrm{S}}=1-S_{\mathrm{S}}=1-\mathrm{e}^{-I_{\mathrm{S}} D_{\mathrm{S}}}\left\{1-\left[1-\mathrm{e}^{-G_{\mathrm{S}} D_{\mathrm{S}}}\right]^{m}\right\} .
$$

We note that the sum of these is not the total fractional cell killing since the cell may be killed by a combination of primaries and secondaries by means of the gamma mechanism. Therefore, we have three fractional cell killing terms:

$$
K_{\mathrm{P}}=1-S_{\mathrm{P}}, \quad K_{\mathrm{S}}=1-S_{\mathrm{S}}, \quad K_{\mathrm{PS}}=1-S_{\mathrm{PS}} .
$$

The total killing is

$$
K=1-S=1-S_{\mathrm{P}} S_{\mathrm{S}} S_{\mathrm{PS}},
$$

so that

$$
\begin{aligned}
K=K_{\mathrm{P}}+K_{\mathrm{S}}+K_{\mathrm{PS}}- & K_{\mathrm{P}} \\
& K_{\mathrm{S}}-K_{\mathrm{P}} K_{\mathrm{PS}} \\
& -K_{\mathrm{S}} K_{\mathrm{PS}}+K_{\mathrm{P}} K_{\mathrm{S}} K_{\mathrm{PS}} .
\end{aligned}
$$

Ratios of $K_{\mathrm{P}} / K, K_{\mathrm{S}} / K$, and $K_{\mathrm{PS}} / K$ are plotted at the
$10 \%$ survival level for the four beams in Fig. 4 . We note that the secondaries kill less than half of the cells for all beams except for the argon beam in the lower right-hand panel.

\section{SPREAD BRAGG PEAKS}

Similar calculations can be made for spread beams that are more typically used in the therapeutic situation. Four of these are shown in Fig. 5, all having spread peaks of $10 \mathrm{~cm}$. Ion and gamma kill coefficients have been calculated for a dose of $1 \mathrm{~Gy}$ incident and are shown in Fig. 6 for both oxic and hypoxict cells. We see in this figure the extent to which gamma kill dominates in both the oxic and hypoxic cases in the plateau regions, while ion kill dominates increasingly in the peak regions for the heavier ion beams. Also seen clearly is the extent to which ion kill varies across the peak region, particllarly in the case of the carbon ions.

Presently, LET spectra obtained with a silicon-germanium detector (the BERKLET) are

$\nmid$ Parameters used for hypoxic cells were: $\sigma_{0}=67 \mu \mathrm{m}^{2} ; \kappa=1300 ; D_{0}=4.6 \mathrm{~Gy}$; and $m=2.5$. 
RELATIVE CELL KILLING FOR 10\% SURVIVAL OXYGENATED CELLS
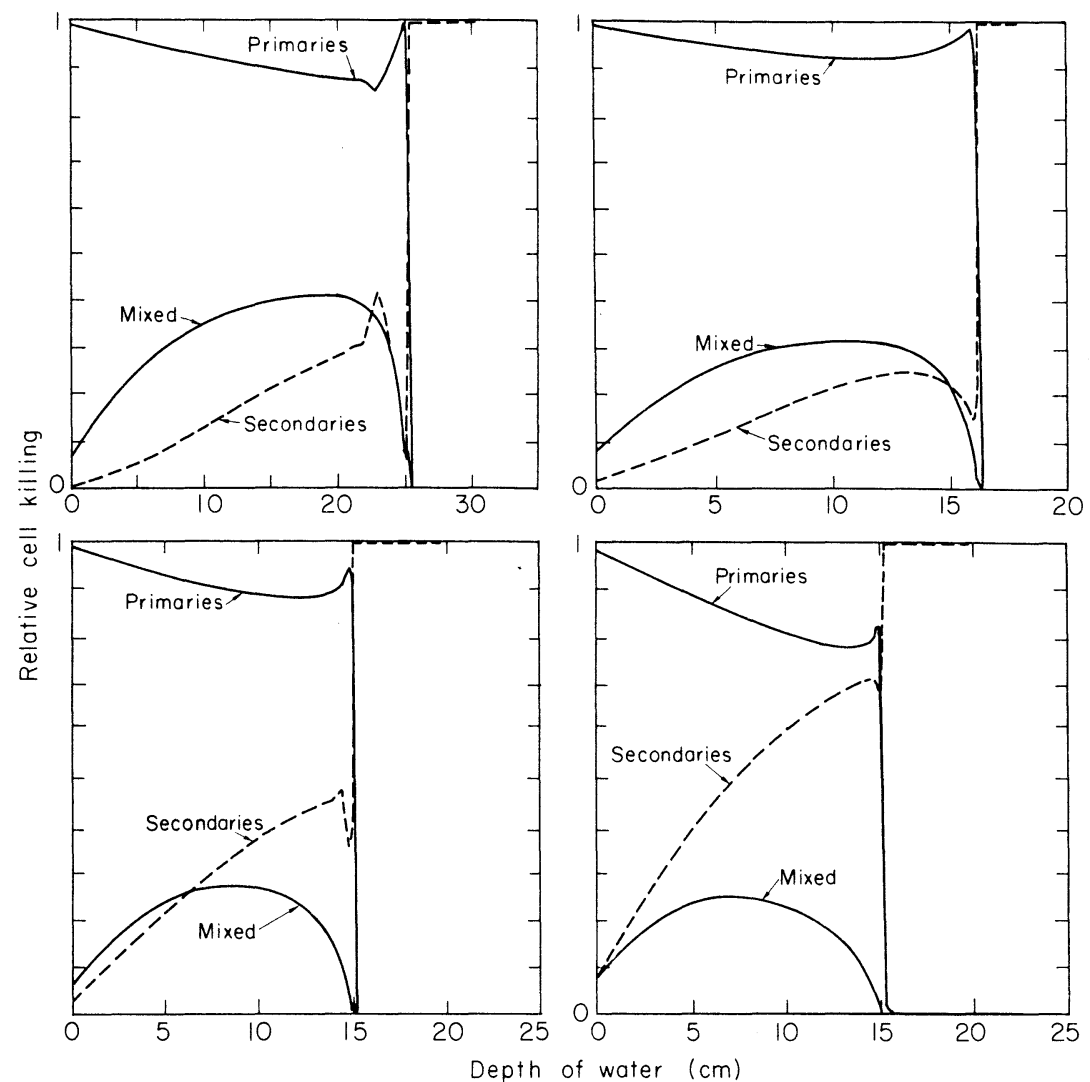

FIG. 4. Fraction of cell kill contributed by each of the three components defined in the text: primaries only, secondaries only, or a combination of primaries and secondaries calculated at the $10 \%$ survival level for the four beams described in Fig. 1.

being used as input to a code that calculates survival using the Katz model as described here as well as other models of cell killing. Comparisons are being made with experimental cell survival data obtained at

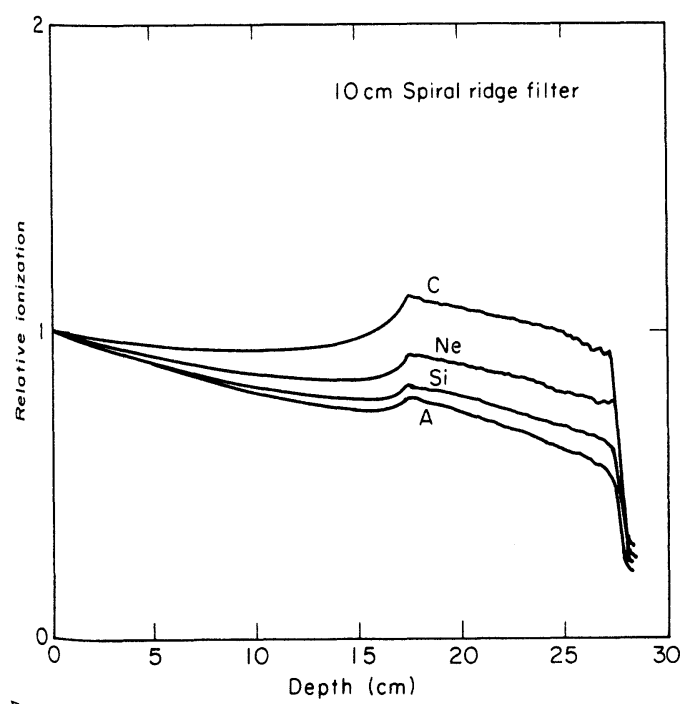

FIG. 5. Central axis dose vs depth curves in water for carbon, neon, silicon, and argon beams spread by a ridge filter to $10 \mathrm{~cm}$ and having a range of $27 \mathrm{~cm}$ of water calculated with the computer code HZESEC. the same positions in the beam that the physical data were obtained.

\section{A CONNECTION BETWEEN THE KATZ MODEL AND OTHER MODELS OF CELL KILLING}

Several other model descriptions of cell killing (Chadwick and Leenhouts, 1981; Kellerer and Rossi, 1978; Roesch, 1978) arrive at cell survival expressions that vary as $\mathrm{e}^{-\alpha D-\beta D^{2}}$ (a linear-quadratic dependence on dose), with varying interpretations of the $\alpha$ and $\beta$ parameters. To avoid confusion, these parameters will be called $a_{1}$ and $a_{2}$ in this paper. Two additional models (Tobias et al., 1980; Curtis, 1986) arrive at survival expressions that approach an exponential slope at high doses and approximate a linear-quadratic dependence at low doses. In the following, we discuss the conditions under which the Katz expression can be linear-quadratic in form at low doses and in this case show that simple relationships exist between parameters of the Katz, the linear-quadratic and LPL (Curtis, 1986) models at low doses and low-LET.

If we rewrite equation (1) as follows:

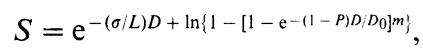


CONTRIBUTION TO ION AND GAMMA FOR OXYGENATED AND HYPOXIC CELLS $10 \mathrm{~cm}$ RIDGE FILTER

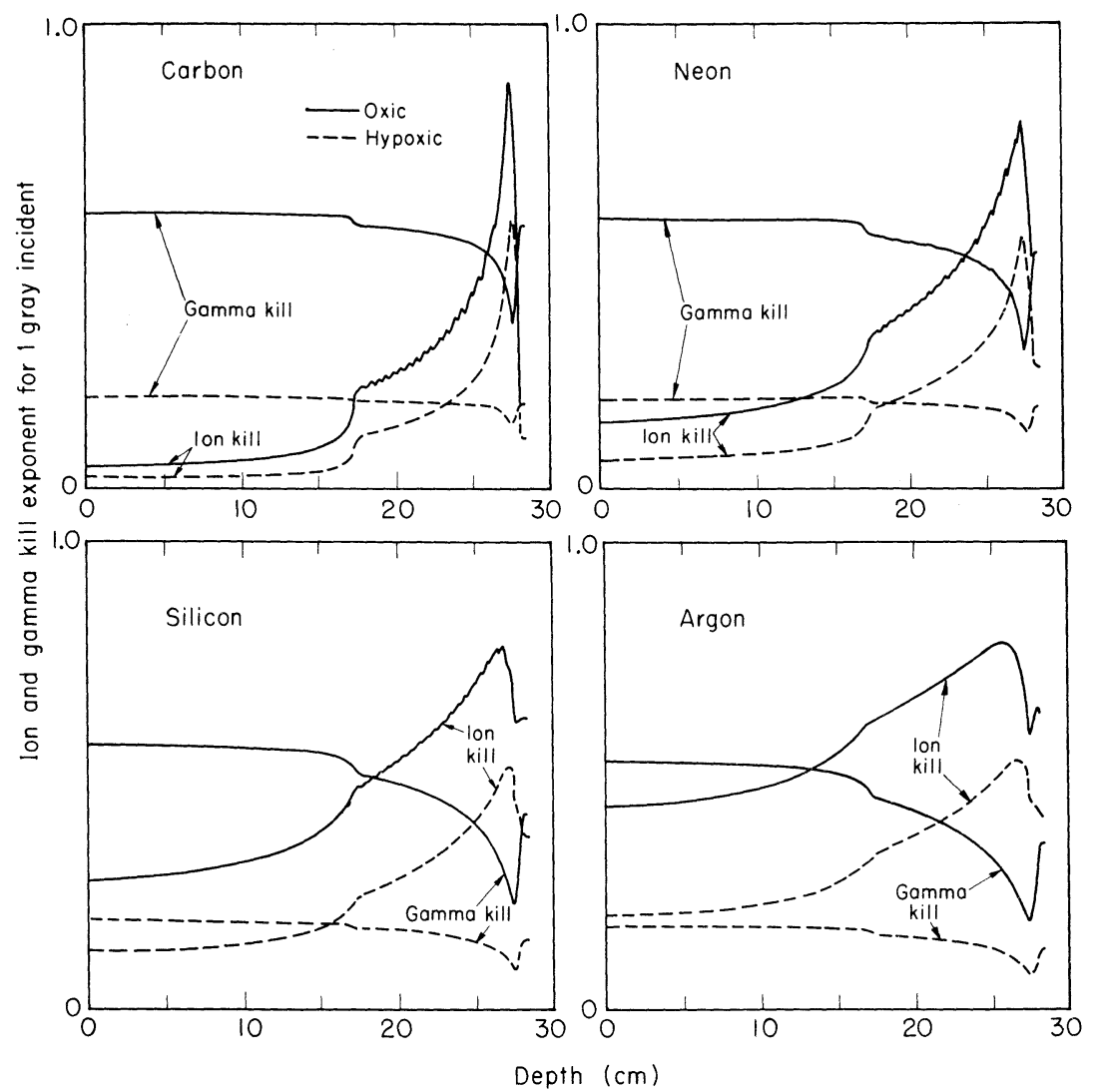

FIG. 6. Ion and gamma kill exponents for oxygenated (solid line) and hypoxic cells (dashed lines) for $1 \mathrm{~Gy}$ incident calculated for the beams described in Fig. 5.

we can work with the negative of the exponent defined as a function of $D$

$$
f(D)=c_{1} D-\ln \left\{1-\left[1-\mathrm{e}^{-c_{2} D}\right]^{m}\right\},
$$

where

$$
c_{1}=\sigma / L \text { and } c_{2}=(1-P) / D_{0} .
$$

We now expand $f(D)$ in a Maclaurin series expansion in powers of $D$ :

$$
\begin{aligned}
f(D)=f(0)+f^{\prime}(0) D+f^{\prime \prime}(0) & \frac{D^{2}}{2 !}+\cdots \\
& +f^{n}(0) \frac{D^{n}}{n !}+\cdots
\end{aligned}
$$

where $f^{n}(0)$ is the $n$th derivative of $f(D)$ evaluated at $D=0$.

Performing the appropriate differentiations, we can calculate the coefficients of the terms in the series. The results are:

$$
\begin{aligned}
f(0) & =0 \\
f^{\prime}(0) & =c_{1} \quad \text { for } m \neq 1 \\
& =c_{1}+c_{2} \text { for } m=1
\end{aligned}
$$

$$
\begin{aligned}
f^{\prime \prime}(0) & =0 \quad \text { for } m \neq 2 \\
& =2 c_{2}^{2} \quad \text { for } m=2 .
\end{aligned}
$$

Therefore, $f(D)$ is linear-quadratic in form if, and only if, $m=2$, and in that case

$$
f(D)=c_{1} D+c_{2}^{2} D^{2}+\cdots
$$

Then, in this case, we can identify $a_{1}$ and $a_{2}$ in the linear-quadratic formulation:

$$
\begin{aligned}
& a_{1}=\frac{\sigma}{L} \\
& a_{2}=\frac{(1-P)^{2}}{D_{0}^{2}} .
\end{aligned}
$$

At high-LET in this formulation, $a_{2}$ tends to zero ( $P$ tends to unity) and $\sigma$ tends to $\sigma_{0}$ so $a_{1}$ decreases as $1 / L$.

At low-LET, we can expand equation (2) in powers of $Z^{* 2} /\left(\kappa \beta^{2}\right)$ and retain only the first term, obtaining

$$
\sigma=\sigma_{0}\left[\frac{Z^{* 2}}{\left(\kappa \beta^{2}\right)}\right]^{2}
$$

and

$$
a_{1}=\frac{\sigma}{L}=\frac{\sigma_{0}}{L}\left[\frac{Z^{* 2}}{\kappa \beta^{2}}\right]^{2}
$$


Also $P \ll 1$, and so

$$
a_{2}=\frac{1}{D_{0}^{2}}
$$

In the LPL model, the linear and quadratic coefficients in the low dose approximation are (Curtis, 1986):

$$
\begin{aligned}
& a_{1}=\eta_{L}+\eta_{\mathrm{PL}} \mathrm{e}^{-\epsilon_{\mathrm{PL}} t_{\mathrm{r}}} \\
& a_{2}=\frac{\eta_{\mathrm{PL}}^{2}}{2 \epsilon}\left(1-\mathrm{e}^{\left.-\epsilon_{\mathrm{PL} t_{r}}\right)^{2},}\right.
\end{aligned}
$$

where $\eta_{\mathrm{L}}$ and $\eta_{\mathrm{PL}}$ are the production per unit absorbed dose of irreparable (lethal) and reparable (potentially lethal) lesions, respectively, $\epsilon_{\mathrm{PL}}$ is the rate per unit time of lesions to be repaired, and $\epsilon$ is the ratio of $\epsilon_{\mathrm{PL}}$ to the rate per unit time of two lesions combining to produce a lethal lesion (binary misrepair).

If we now consider only delayed plating experiments for cells in plateau phase, we have complete repair and $t_{\mathrm{r}} \gg 1 / \epsilon_{\mathrm{PL}}$. This yields

$$
\begin{gathered}
a_{1}=\eta_{\mathrm{L}}=\frac{\sigma_{\mathrm{L}}}{L}=\frac{\sigma_{0}}{L}\left\{1-\left[\mathrm{e}^{-k Z^{* 2 / \beta 2}}\left(1+\frac{k Z^{* 2}}{\beta^{2}}\right)\right]^{n}\right\} \\
a_{2}=\frac{\eta_{\mathrm{PL}}^{2}}{2 \epsilon}=\frac{\sigma_{0}^{2} F_{c}^{2} n^{2} k^{2}\left(Z^{* 2} / \beta^{2}\right)^{2}}{2 L^{2} \epsilon} \mathrm{e}^{-2 k Z^{* 2 / \beta 2}}
\end{gathered}
$$

where $k, n, \sigma_{0}$, and $F_{\mathrm{c}}$ are parameters of the LPL model. Here $\sigma_{0}$ has the same meaning as in the Katz model, $k$ relates the probability of producing a lesion which may become a potentially lethal lesion to the charge and velocity of the charged particle, $n$ is the mean number of times a charged particle track traverse targets (a critical region along the DNA helix) in passing through a cell, and $F_{\mathrm{c}}$ is a measure of how many potentially lethal lesions are not restituted (chemically repaired).

The low-LET approximation yields

$$
a_{1}=\frac{\sigma_{0} n k^{2}\left(Z^{* 2} / \beta^{2}\right)^{2}}{2 L}
$$

and

$$
a_{2}=\frac{\sigma_{0}^{2} F_{c}^{2} n^{2} k^{2}\left(Z^{* 2} / \beta^{2}\right)^{2}}{2 L^{2} \epsilon} .
$$

Finally, we can equate appropriate constants linking the Katz and LPL models for $m=2$ and for fully repaired cells from equations (26) and (32), (27) and (33). The result is shown in Table 1.
Table 1. Link of constants* in the Katz and LPL models

\begin{tabular}{cc}
\hline Katz & LPL \\
\hline$\kappa$ & $\frac{(2 / n)^{1 / 2}}{k}$ \\
{$[m=2]$} & - \\
$\sigma_{0}$ & $\sigma_{0}$ \\
$D_{0}$ & $\frac{L(2 \epsilon)^{1 / 2}}{\sigma_{0} F_{c} n k\left(Z^{* 2} / \beta^{2}\right)}$ \\
\hline
\end{tabular}

*See text for definitions of the constants.

An interesting conclusion is that according to the LPL model, $D_{0}$ is not exactly independent of LET but varies as the ratio $L /\left(Z^{* 2} / \beta^{2}\right)$. Since LET is roughly proportional to $\left(Z^{* 2} / \beta^{2}\right)$, this variation is small and probably could not be detected in experimental data.

Acknowledgements - It is a pleasure to acknowledge the conversation with Dr John Dicello which motivated the calculations in the latter half of this paper. The expert typing of Ms Tennessee Gock is greatly appreciated. This research was supported in part by Public Health Service Grants CA15184 and CA23247 awarded by the National Cancer Institute, and by the U.S. Department of Energy under Contract DE-AC03-76SF00098.

\section{REFERENCES}

Chadwick K. H. and Leenhouts H. P. (1981) The Molecular Theory of Radiation Biology. Springer, New York.

Curtis S. B. (1977) Calculated LET distributions of heavy ion beams. Int. J. Radiat. Oncol. Biol. Phys. 3, 87-91.

Curtis S. B. (1986) Lethal and potentially lethal lesions induced by radiation-a unified repair model. Radiat. Res. 106, 252-270.

Katz R., Ackerson B., Homayoonfar M. and Sharma S. C. (1971) Inactivation of cells by heavy ion bombardment. Radiat. Res. 47, 402-425.

Kellerer A. M. and Rossi H. H. (1978) A generalized formulation of dual radiation action. Radiat. Res. 75, $471-488$.

Roesch W. C. (1978) Models of the radiation sensitivity of mammalian cells, in 3rd Symp. Neutron Dosim. Biol. Med. (Edited by Burger G. and Ebert H. G.), pp. 1-27. Commission of the European Communities, Luxembourg.

Tobias C. A., Blakley E. A., Ngo F. Q. H. and Yang T. C. H. (1980) The repair-misrepair model of cell survival. In Radiation Biology and Cancer Research (Edited by Meyn R. E. and Withers H. R.), pp. 195-230. Raven, New York.

Todd P. (1967) Heavy-ion irradiation of cultured human cells. Radiat. Res. Suppl. 7, 196-207. 